\title{
Resumen de Tesis: “Historiografía y política en el Reino Unido. La disputa ideológica entre las Historias de Grecia de W. Mitford y G. Grote"1
}

\author{
Luis Eduardo Fierro \\ (Universidad Nacional de Córdoba) \\ lefvarch@hotmail.com
}

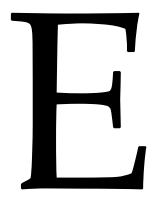

1 uso de la historia con fines políticos ha sido una herramienta en extremo valorada por las elites gobernantes a lo largo de la historia, por lo que estudiar uno de estos procesos me ha parecido de suma utilidad. En este trabajo final de licenciatura, me centré en el estudio de dos obras sobre la antigua Grecia escritas en momentos en que el régimen parlamentario británico comenzaba a consolidarse; un tiempo en el que la democracia y la profesionalización de la política no solo iban a producir una revolución en Gran Bretaña, sino que atravesarían las fronteras de todo el mundo. Pero no solo la política iba a cambiar sus paradigmas, también lo haría el modo de escribir la historia.

En ese contexto, se produjo una de las primeras controversias intelectuales con respecto a la interpretación de la historia griega clásica. La misma se produjo poco antes de la "profesionalización" de los estudios clásicos en Gran Bretaña. Sus protagonistas fueron dos políticos aficionados a la historia de Grecia antigua, que buscaron leer la misma a la luz de las vicisitudes políticas británicas contemporáneas. William Mitford (1744-1827), un tory que publicó los diez volúmenes de su The History of Greece entre 1784 y 1810, y, entre 1846 y 1856, George Grote (1794-1871), un radical reformista del partido whig, que publicó su A History of Greece en doce volúmenes.

Ambos autores, con una profunda lectura de la problemática sociopolítica de su tiempo, propusieron respuestas propias y apelaron, para ello, a la reflexión sobre la experiencia histórica griega y a apropiarse del pasado en función de sus presentes. En la tesis se exploró de qué forma la "revolución" se convirtió en un hilo conductor para sus interpretaciones históricas. Uno, un historiador georgiano, Mitford, que desde la

\footnotetext{
${ }^{1}$ Trabajo Final de Licenciatura en Historia defendido el 18 de mayo de 2018 en la Universidad Nacional de Córdoba (UNC); dirigido por el Dr. Álvaro Moreno Leoni. Miembros del jurado evaluador: Dr. Álvaro Moreno Leoni (UNC/CONICET); Dr. Eduardo Escudero (UNRC/UNC); Dr. Agustín Moreno (UNC/CONICET). Calificación obtenida: 10 (diez).
} 
Ilustración se preocupará por el avance de la multitud ociosa en la política griega antigua. El otro, el victoriano Grote, que, desde el positivismo, interpretará a la revolución como una parte de la evolución propia de lo político. En sus obras, ambos establecerán una elipsis de más de 2.000 años entre su experiencia temporal y la de la antigüedad clásica, que, para ambos, era continuada por Gran Bretaña como su legítima heredera.

En el trabajo final, situé esta polémica también, no solo en un contexto de cambio político, sino también historiográfico, puesto que estas dos obras fueron escritas durante las décadas previas a la profesionalización de los estudios clásicos en las islas británicas. Dicho momento estuvo enmarcado en un proceso de cambio y redefinición de la conciencia histórica que R. Koselleck caracterizó como el Sattelzeit, período "silla de montar", que implicaba el paso del modelo antiguo de la historia magistra vitae, construida en torno a exempla del pasado, al historicismo que propugnaba el carácter único de los acontecimientos históricos. En el caso británico, que es el que estamos analizando, el primero de los autores mencionados, Mitford, se encontraba al principio de dicho proceso y, el segundo, Grote, en sus postrimerías.

He abordado las trayectorias de ambos historiadores británicos, en política y en la vida intelectual y, en particular, se ha intentado llamar la atención sobre el impacto de sus obras históricas sobre la Grecia antigua en la sociedad británica de su tiempo. La obra de Mitford se presentaba claramente como un producto bastante representativo de la gentry rural enriquecida, en el que el interés principal radicaba en el ataque a la visión positiva de la democracia ateniense en auge, sobre todo, a partir de la Revolución Americana. Por su parte, sin dejar de representar a su grupo político y a su base social, la burguesía urbana y parte de la gentry rural, Grote conseguirá escribir una obra académica (aunque dirigida también a un público amplio). Aunque entró en diálogo crítico con la obra de su antecesor, su intención era que A History of Greece tuviera peso intelectual por sí misma y que, de alguna manera, reemplazara o corrigiera antiguas y equivocadas interpretaciones de la historia antigua griega.

También he advertido en nuestro estudio que en ambos historiadores existe una preocupación especial por el fenómeno revolucionario y que, tanto Mitford como Grote, no advirtieron problemas en aplicar el concepto moderno de revolución a la historia griega. Esto los condujo a despreocuparse, incluso, por la exactitud de los hechos narrados en sus obras, así como también por algunos problemas vinculados a una interpretación anacrónica de los mismos, en general, debido a su interés por contribuir al debate político contemporáneo usando ejemplarmente la historia antigua griega.

Los problemas inherentes a la era de las revoluciones, entonces, subyacen fuertemente en las obras de ambos autores. La independencia de las colonias americanas, y el periodo del terror jacobino durante la Revolución Francesa, pondrán en serio riesgo a la misma clase social en la que Mitford se veía representado. Las revoluciones burguesas de la primera mitad del siglo XIX, por otra parte, serán interpretadas por Grote como parte de una "evolución" necesaria, capaz de dar impulso a un cambio en la 
política, no solo de Gran Bretaña, sino de toda Europa. Mitford, autor contemporáneo del proceso revolucionario, advertirá en su obra hasta qué punto la Revolución Francesa había producido una serie de cambios en la situación política inglesa. Grote, por su parte, es testigo de la "reconstrucción" de una Europa que solo preserva el recuerdo del "terror revolucionario"

Se recorrió, en un principio, la historia del concepto de "revolución", partiendo del siglo XVIII como una consecuencia intelectual de la Revolución Francesa y la génesis del mundo contemporáneo. Esto reveló los problemas experimentados por ambos autores a la hora de insertar esta preocupación en sus narrativas sobre el pasado griego clásico. Al respecto, fueron notables las interpretaciones del gobierno de los Treinta Tiranos en Atenas, que fue asociado, por Mitford, al desarrollo último del accionar democrático, pese a que se trataba de un gobierno manifiestamente oligárquico. Culpará así al despotismo de la "mob-rule" de haber diseminado la corrupción desde Atenas, y de haber erosionado incluso las firmes bases político-sociales de la propia Esparta, a la cual considera un verdadero modelo político. El autor tenía una severa aprehensión por la democracia griega, y no dudó así en tacharla de oclocracia, "gobierno de la muchedumbre", que era el término despectivo utilizado por los pensadores griegos, desde Aristóteles en adelante, para referirse a la degradación del ideal democrático por la falta de control (Paiaro, 2018).

Grote, por el contrario, manifestó un interés específico en estudiar el avance pleno de las instituciones democráticas en la Grecia antigua de la mano de líderes políticos como Pericles, Demóstenes y, extrañamente, Cleón, caracterizado por la incorporación política de estratos de la población que antes se encontraban marginados de la participación política. Esto coincidía, según el punto de vista liberal radical de Grote, con un proceso de "evolución" política, similar al que se estaba produciendo en la Gran Bretaña de su tiempo. Sin embargo, fue la redención de la figura política de Cleón la que ocasionará que Grote entre en conflicto con una parte de la intelectualidad conservadora de la época, por ejemplo, a partir del panfleto publicado en su contra por Richard Shilleto (1851), que intentó impugnar la autoridad del historiador inglés y su competencia académica en la crítica e interpretación de las fuentes literarias clásicas.

Las obras de Mitford y Grote no solo van a ser parte de una disputa ideológica e intelectual. También en el campo político, ambos autores se van a convertir en representantes de dos paradigmas de país, pero, sobre todo, de dos visiones distintas del Imperio Británico, que había evolucionado a partir de un puñado de exitosos enclaves comerciales sin mayores responsabilidades políticas en el siglo XVII, para convertirse en la administración de la tercera parte del globo un siglo más tarde. Para 1704, Gran Bretaña era el país más rico del mundo y el imperio más poderoso conocido hasta el momento, pero también se extendió la idea de que se trataba de un imperio equivocado, construido sobre la espalda de pueblos nativos y millones de esclavos extraídos de 
África, más parecido al imperio ateniense, que Mitford tanto aborrecía, que, al imperio moral y espartano, que su frenesí literario intentaba mostrar como modelo de moralidad.

A diferencia del imperio equivocado, el imperio de las buenas intenciones comenzó a tener peso político e intelectual en la década de los 1830. Uno de sus promotores: Thomas Babington Macaulay, quien fue uno de los que elaboró la teoría de la autoliquidación, la cual afirmaba, entre otras cosas, que una vez que los británicos hubieran compartido sus bienes morales y materiales con las antiguas sociedades oprimidas por la pobreza y la tiranía, y les hubieran enseñado a valerse por sí mismas en un justo juego democrático, los británicos harían sus maletas y volverían a casa. Pero este sueño liberal intelectual estuvo muy lejos de ser consumado, por lo menos, en vida de Macaulay y del grupo de pensadores y políticos que sustentaban esta visión imperial.

Tanto el filósofo John Stuart Mill, como Grote, que compartían esta lectura, veían a Gran Bretaña como la legítima heredera de la democracia ateniense, y que tenía a su vez un rol histórico que cumplir llevando el progreso a los demás pueblos del orbe. El Imperio Británico era para ellos una fuerza del bien en el mundo, y todo su andamiaje colonial y militar se ocupaba, o se enfrentaba, solo contra déspotas y, si alguna vez era derrotado, ello podía constituir un desastre para la civilización. Después de todo, este proceso, para ellos, había ocurrido también en el pasado, unos 2.300 años antes con Atenas, a cuya experiencia buscaban asociarse.

Además, estas visiones sobre el imperio tenían una incidencia directa en las concepciones sobre la política interna, en Gran Bretaña y en Atenas. Las constantes referencias a una "multitud ociosa" que, por los avatares de la política democrática de la Grecia antigua, quedaba a cargo de asuntos tan importantes como la gestión de la justicia, la administración del Estado, pero, sobre todo, de la conducción política del Imperio Ateniense, poblarán las páginas de Mitford, convirtiéndose en una verdadera obsesión para el autor. Por el contrario, el devenir político de una Atenas burguesa, signada por una era de grandes transformaciones, va a ser la preocupación central de Grote, quien veía a la política británica de su tiempo como la continuación natural de la política que se había desarrollado y llegado a existir en la Atenas de la antigua Grecia, y que se había mostrado incapaz de resistir al embate monárquico de Macedonia en el siglo IV a.C. por no haber ampliado lo suficiente la participación y la libertad del pueblo.

La idea de progreso y evolución durante la era victoriana, entonces, será una influencia central en la visión utilitarista que Grote va a tener del pasado, donde la libertad, la justicia y la revolución mismas se van a adecuar a una perspectiva burguesa y capitalista, en la que la "revolución" será parte de un proceso lineal de cambio irrepetible sin retorno. Las "revoluciones" para Mitford serán, en cambio, una consecuencia destructiva natural de la democracia, del ejercicio del poder en manos de la multitud ociosa incapaz de asumir la administración de asuntos tan importantes como la justicia, el gobierno y, por último, del imperio. Ambas experiencias, la antigua y la moderna, no diferían en lo absoluto, excepto por los actores, puesto que, para Mitford, 
las revoluciones habían fracasado en la Antigüedad y no había motivos para que no volvieran a hacerlo en la Modernidad.

En cuanto a la recepción de ambas obras, he advertido que puede decirse que la de Mitford será de corto aliento. La de Grote y la de su entorno intelectual, en cambio, será ciertamente exitosa. Sus volúmenes sobre Grecia lograrán situar al historiador como un sujeto competente y de autoridad en el tema. Por más que su A History of Greece parece haberse escrito a la medida de una respuesta historiográfica a Mitford, sus postulados la trascenderán y se van a convertir en referentes para toda su generación, contribuyendo a generar cambios políticos y culturales.

Ambos autores, en sus correspondientes periodos de tiempo y, en consecuencia, con las ideas de cada uno, respondieron a las necesidades de las facciones del partido al que pertenecían, así como también abrieron el camino a indagaciones más académicas sobre el pasado griego antiguo. El periodo clásico de la historia de Grecia fue un periodo convulsionado de la historia, así como lo fue también el periodo revolucionario moderno contemporáneo que tocó vivir a los autores, algo que les condicionará, e impulsará, para construir una visión de Grecia estrechamente vinculada con sus respectivos presentes.

\section{Bibliografía}

Paiaro, D. (2018). Entre el "gobierno de la muchedumbre" y la "dictadura del proletariado". La historiografía de la democracia ateniense frente al espejo de la revolución. En A. M. Moreno Leoni y A. Moreno (Eds.), Historiografía Moderna y Mundo Antiguo (1850-1970) (pp. 108-118). Córdoba: Tinta Libre.

Shilleto, R. (1851). Thucydides or Grote? Londres: John Deighton.

Para citar este resumen:

Fierro, Luis Eduardo (2018). Resumen de Tesis: “Historiografía y política en el Reino Unido. La disputa ideológica entre las Historias de Grecia de W. Mitford y G. Grote". Anuario de la Escuela de Historia Virtual, 14, 127-131. 